\title{
Interaction of head and neck squamous cell carcinoma cells and mesenchymal stem cells under hypoxia and normoxia
}

\author{
CHRISTIAN WILHELM $^{1}$, AGMAL SCHERZAD ${ }^{1}$, MAXIMILIAN BREGENZER ${ }^{1}$, TILL MEYER ${ }^{1}$, \\ THOMAS GEHRKE ${ }^{1}$, NORBERT KLEINSASSER ${ }^{2}$, RUDOLF HAGEN ${ }^{1}$ and STEPHAN HACKENBERG ${ }^{1}$ \\ ${ }^{1}$ Department of Otorhinolaryngology, Plastic, Aesthetic and Reconstructive Head and Neck Surgery, \\ Julius Maximilian University of Wuerzburg, D-97080 Wuerzburg, Germany; ${ }^{2}$ Department of Otorhinolaryngology, \\ Head and Neck Surgery, Kepler University, A-4020 Linz, Austria
}

Received February 1, 2020; Accepted July 23, 2020

DOI: $10.3892 / 01.2020 .12092$

\begin{abstract}
Mesenchymal stem cells (MSCs) exhibit strong tropism towards tumor tissue. While MSCs generally surround tumors, they can also infiltrate tumors and thereby influence their proliferation. Interactions between MSCs and tumor cells are usually tested under normoxia, but the majority of solid tumors, including head and neck squamous cell carcinoma (HNSCC), are also characterized by hypoxic areas. Hence, the present study aimed to assess the interaction between MSCs and tumor cells under hypoxic conditions. MSCs were cultivated under normoxia and hypoxia, and conditioned media were used to cultivate the HNSCC cell line FaDu. The cell cycle distribution and viability of MSCs and the proliferation of FaDu cells were analyzed under normoxia and hypoxia, and changes in cytokine levels in the conditioned media were evaluated. No cell cycle changes were observed for MSCs after $24 \mathrm{~h}$ of cultivation under hypoxia, but the cell viability had declined. Hypoxia also led to a decrease in the proliferation of FaDu cells; however, FaDu cells proliferated faster after $48 \mathrm{~h}$ under hypoxia compared with normoxic conditions.
\end{abstract}

Correspondence to: Dr Christian Wilhelm, Department of Otorhinolaryngology, Plastic, Aesthetic and Reconstructive Head and Neck Surgery, Julius Maximilian University of Wuerzburg, 11 Josef-Schneider-Strasse, D-97080 Wuerzburg, Germany E-mail: wilhelm_c2@ukw.de

Abbreviations: DMEM, Dulbecco's Modified Eagle's Medium; FACS, fluorescence-activated cell sorting; FaDu-fre, FaDu cells incubated in fresh DMEM with supplements; FaDu-hyp, FaDu cells incubated in hypoxic preconditioned MSC supernatant; FaDu-nor, FaDu cells incubated in normoxic preconditioned MSC supernatant; FCS, fetal calf serum; HNSCC, head and neck squamous cell carcinoma; IL-6, interleukin-6; ISCT, International Society for Cellular Therapy; MCP-1, monocyte chemoattractant protein-1; MSCs, mesenchymal stem cells

Key words: mesenchymal stem cells, head and neck squamous cell carcinoma, hypoxia, normoxia, $\mathrm{FaDu}$, cell cycle, proliferation, interleukin-6
This effect was reversed after incubation under normoxia for $72 \mathrm{~h}$ and hypoxia for $72 \mathrm{~h}$. While these changes constituted a trend, these differences were not statistically significant. A cytokine assay showed an increase in interleukin (IL)- 6 in the hypoxic medium. Overall, the results indicated that there was an interaction between MSCs and tumor cells. The presence or absence of oxygen seemed to influence the functionality of MSCs and their protumorigenic properties, in which IL-6 was identified as a potential mediator. Since MSCs are a component of the tumor stroma, further in vitro and in vivo studies are needed to investigate this interaction in order to develop novel approaches for tumor therapy.

\section{Introduction}

The oxygen concentration in malignant tumors is heterogeneous, and hypoxic intratumoral areas are caused by inadequate oxygen supply to rapidly proliferating tumor cells (1). Compared with healthy tissue of the neck, certain areas of untreated head and neck squamous cell carcinoma (HNSCC) tissue are less oxygenated because the rapidly proliferating tumor outgrows its blood supply (2). Due to decreased levels of chemotherapeutic drugs and intrinsic radiation resistance of hypoxia areas, tumor hypoxia is one of the primary causes of the limited therapeutic success in malignancies (3). Hence, the development of new therapeutic strategies is needed.

There have been promising reports about functionalized nanoparticles, cytokine-based tumor therapies and cell-based drug delivery systems (4,5). Such cell-based therapies can be achieved by using mesenchymal stem cells (MSCs), the effect of which on tumor cells is controversial because there is evidence for both tumor inhibition and tumor progression by MSCs (6). MSCs are multipotent progenitor cells that support the homing, self-renewal and differentiation of hematopoietic stem cells in bone marrow (7). The International Society for Cellular Therapy (ISCT) proposed three criteria to define human MSCs: i) The cells must adhere to plastic; ii) they must express CD105, CD73 and CD90 and do not express CD45, CD34, CD14 or CD11b, CD79 $\alpha$ or CD19 or HLA-DR surface molecules and iii) they must differentiate into osteoblasts, adipocytes and chondroblasts in vitro $(8,9)$. 
Furthermore, MSCs can leave their site of origin and reach injured or inflamed tissue via the bloodstream $(10,11)$. In some tissues, such as skeletal muscle and fat, MSCs can be derived from perivascular cells (12). In addition to their capability to promote the regeneration of damaged tissue, MSCs tend to migrate towards tumor cells and even invade the tumor $(13,14)$. However, the interactions between MSCs and various tumor cells differ, since the current literature describes both increased tumor progression due to interactions with MSCs as well as the antiproliferative effects of MSCs in tumors $(15,16)$. Notably, cancer stem cells, which are part of the tumor microenvironment, have been shown to promote both tumor growth and the immune responses against cancer via stimulation by neurotrophins (17).

However, hypoxia itself can also have beneficial effects and thus be of therapeutic value. In MSCs, hypoxia increases the secretion of growth factors, such as vascular endothelial growth factor, which induces angiogenesis, as well as anti-inflammatory molecules, such as prostaglandin E2, leading to enhanced immune-modulating activities $(18,19)$. For instance, hypoxic preconditioning could restore neurological function in a rat model of traumatic brain injury to a greater extent compared with normoxic media (20). In a murine stroke model, hypoxic preconditioning decreased the infarct volume (21). In a murine hepatectomy model, hypoxia-preconditioned MSCs promoted liver regeneration (22). MSCs themselves can decrease their energy demands and increase their proliferative capacity under hypoxia, suggesting an adaption to a hypoxic environment in hypoxic tumor areas (23).

However, the interaction of MSCs and tumor cells has mostly been tested under normoxic conditions, and this interaction under hypoxia has been neglected. Therefore, the present study aimed to analyze MSC-dependent cytokine secretion and the effect of MSCs on the HNSCC cell line FaDu under hypoxic and normoxic conditions.

\section{Materials and methods}

MSC isolation. MSCs were isolated from the human bone marrow of five voluntary trauma patients who were undergoing surgery in the Department of Orthopedics (Koenig-Ludwig-Haus, Wuerzburg). The median age of these patients was 64 years and the age ranged from 49 to 77 years. These patients comprised three men and two women. The study was approved by the Ethics Committee of the Medical Faculty, University of Wuerzburg (Wuerzburg, Germany; approval no. 72/06), and written informed consent was obtained from all patients. MSCs were isolated according to the methods of Lee et al (24) by using Ficoll density gradient centrifugation (30 min; $318 \mathrm{x} \mathrm{g}$; density=1,077 g/ml). After collection of the cells from the interphase, several washing steps with phosphate-buffered saline (PBS) (Roche Diagnostics GmbH) containing $2 \%$ fetal calf serum (FCS; Linaris) were performed. The isolated cells were resuspended in Dulbecco's Modified Eagle's Medium (DMEM) (Gibco; Thermo Fisher Scientific, Inc.), supplemented with $10 \%$ FCS and $1 \%$ penicillin/streptomycin (Sigma-Aldrich; Merck KGaA). After incubation overnight at $37^{\circ} \mathrm{C}$ and $5 \% \mathrm{CO}_{2}$ in DMEM with supplements, the tissue culture plates were washed to remove residual non-adherent cells. Every 2 days, the medium was changed.
Cell morphology, surface molecules and differentiation to osteoblasts and adipocytes were investigated using a fluorescence microscope (Leica DMI 4000B inverted microscope; Leica Microsystems $\mathrm{GmbH}$ ) and by fluorescence-activated cell sorting (FACS; FACSCanto; BD Biosciences) according to the ISCT criteria.

MSC conditioning. MSCs were first seeded on culture plates in DMEM with the aforementioned supplements and incubated overnight at $37^{\circ} \mathrm{C}$ in $21 \% \mathrm{O}_{2}$ and $5 \% \mathrm{CO}_{2}$. Half of the plates were then incubated in an anaerobic jar (2.5 1; Merck KGaA), while the other half of the plates were further incubated under normoxia. One culture plate was removed from each condition after 3, 6 and $24 \mathrm{~h}$. The supernatant was resuspended, centrifuged at $47 \mathrm{x} \mathrm{g}$ at room temperature for $5 \mathrm{~min}$ and frozen at $-20^{\circ} \mathrm{C}$ for later use in a cytokine assay and $\mathrm{FaDu}$ proliferation analysis. Cells on the plate were trypsinized with $0.25 \%$ trypsin (Gibco; Thermo Fisher Scientific, Inc.), resuspended in DMEM with supplements and centrifuged at $47 \mathrm{x} g$ at room temperature for $5 \mathrm{~min}$. The pellets from both centrifugation steps were resuspended in $500 \mu 1$ DMEM with supplements for both the MSC viability test and cell cycle analysis.

MSC viability test. The number of viable MSCs after conditioning in the hypoxic chamber was determined using a Neubauer chamber and the trypan blue exclusion test. Non-viable cells were stained blue due to cell membrane defects, and cell viability was assessed in accordance with the ability of cells to exclude the dye. In total, $3 \times 10^{4}$ cells per group were subjected to cytospin centrifugation. Cells accumulated on a small area on a glass slide by centrifugation at $10,000 \mathrm{x} \mathrm{g}$ at room temperature for $5 \mathrm{~min}$ in a cytocentrifuge. The slides were then stored for $2 \mathrm{~h}$ in pure methanol at $-20^{\circ} \mathrm{C}$. To visualize cellular DNA, the cells were incubated with $1 \mu \mathrm{g}$ bisbenzimide (Sanofi S.A.) per ml of DMSO for three min. Afterwards, MSC viability was evaluated by counting micronuclei and mitotic cells using a fluorescence microscope (magnification $\mathrm{x} 400$ ). The viability test was performed four times.

Cell cycle analysis in MSC. For cell cycle analysis, MSCs were fixed in ice-cold $70 \%$ ethanol at $4^{\circ} \mathrm{C}$ for $2 \mathrm{~h}$ in the dark. Then, $500 \mathrm{ml} \mathrm{PI} / \mathrm{RNase}$ Staining Buffer (Becton, Dickinson and Company) was added before the samples were incubated again at $4^{\circ} \mathrm{C}$ in the dark for $15 \mathrm{~min}$ and immediately examined using FACS (FACSCanto) and BD FACSDiva software version 5.0.3 (both Becton, Dickinson and Company). The analysis was performed four times.

MSC supernatant cytokine assay. The dot blot assay (RayBio ${ }^{\circledR}$ C-Series Human Cytokine Antibody Array C3, Raybiotech, Inc.) was used as a semiquantitative method to analyze MSC cytokine secretion. The frozen supernatants of the samples after $24 \mathrm{~h}$ of incubation under normoxia or hypoxia were thawed at room temperature and investigated for the presence of cytokines. The assay was performed according to the manufacturer's protocol. The membrane was blocked for $30 \mathrm{~min}$ at room temperature and incubated with the sample overnight at $4^{\circ} \mathrm{C}$. After two washing steps of $5 \mathrm{~min}$ at room temperature, the membrane was incubated with the biotinylated antibody cocktail for $1,5 \mathrm{~h}$ at room temperature. After two more 
washing steps of $5 \mathrm{~min}$ at room temperature, the membrane was incubated with HRP-Streptavidin for $2 \mathrm{~h}$ at room temperature. Labeled proteins were observed by enhanced chemiluminescence using detection buffer and exposure to X-ray film (Amersham; Cyvita). The X-ray film was scanned and evaluated using ImageJ (version 10.2, National Institutes of Health). The concentrations of the cytokines are represented as dots with different intensities and sizes.

FaDu cell proliferation analysis. FaDu HNSCC cells (25) were obtained from the American Type Culture Collection. Cells were cultured in DMEM with the aforementioned supplements. Every third day, the medium was replaced. After reaching 70-80\% confluence, the cells were trypsinized, washed with PBS, counted and seeded on culture plates. In total, of $2 \times 10^{5} \mathrm{FaDu}$ cells per group were incubated on 12 culture plates for $24 \mathrm{~h}$ at $37^{\circ} \mathrm{C}$ in $21 \% \mathrm{O}_{2}$ and $5 \% \mathrm{CO}_{2}$. Six culture plates each were then incubated in a hypoxic chamber or under normoxia for an additional $24 \mathrm{~h}$. Two plates each under hypoxia or normoxia were then incubated with either fresh DMEM with supplements, MSC/normoxia conditioned medium or MSC/hypoxia conditioned medium. Cells were counted electronically using a Casy ${ }^{\circledR}$ Cell Counter and Analyzer system (Roche Innovatis AG) after 48 and $72 \mathrm{~h}$. The proliferation analysis was performed three times.

Statistical analysis. All data were transferred to standard spreadsheets and analyzed using GraphPad Prism version 6.07 software (GraphPad Software, Inc.). Since the effects of multiple factors were assessed (different degrees of oxygenation in different media for different incubation times), two-way ANOVA was performed to evaluate statistical significance. As a correction for multiple testing, Tukey's multiple comparison test was performed. $\mathrm{P}<0.05$ was considered to indicate a statistically significant difference.

\section{Results}

MSC viability test. The proportions of MSCs containing micronuclei after 3, 6 and $24 \mathrm{~h}$ under hypoxia were 2.1, 3.0 and $2.4 \%$, respectively, while under normoxia the proportions were $2.2,2.4$ and $3.4 \%$, respectively. These differences were not statistically significant $(\mathrm{P}=0.42$ for different incubation times and $\mathrm{P}=0.69$ for different levels of oxygenation, Fig. 1). The percentage of mitotic MSCs after 3, 6 and $24 \mathrm{~h}$ under hypoxia were $0.3,0.5$ and $0.1 \%$, respectively, while those under normoxic conditions were $0.2,0.3$ and $0.8 \%$, respectively. These differences were not statistically significant $(\mathrm{P}=0.70$ for different incubation times and $\mathrm{P}=0.34$ for different levels of oxygenation, Fig. 2).

Cell cycle analysis in MSCs. The proportions of MSCs under hypoxia in the $\mathrm{G}_{0} / \mathrm{G}_{1}, \mathrm{~S}$ and $\mathrm{G}_{2} / \mathrm{M}$ phases were 93.0, 2.2 and $4.4 \%$, respectively. After $24 \mathrm{~h}$ under normoxia, the corresponding proportions were $94.5,1.8$ and $3.4 \%$, respectively. These differences were not statistically significant $(\mathrm{P}=0.82$ for different incubation times; Figs. 3 and 4).

MSC supernatant cytokine assay. MSCs released different cytokines and growth factors responsible for inflammation,

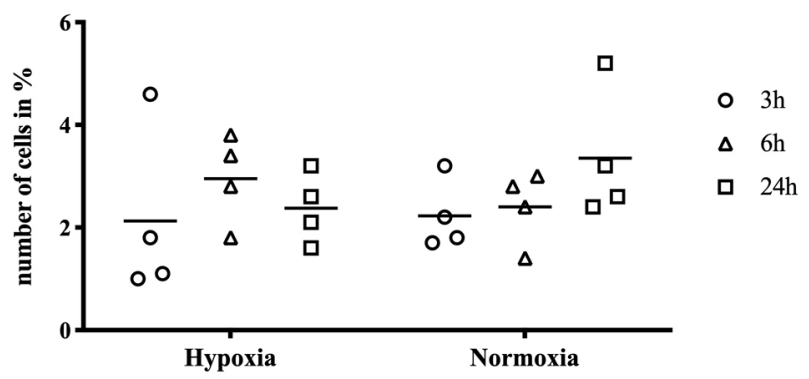

Figure 1. Proportion of MSCs containing micronuclei after incubation under hypoxia and normoxia. Between 2.1 and $3.4 \%$ of MSCs under hypoxia and normoxia contained micronuclei. The experiments were independently performed four times, and the lines on the graph show the arithmetic mean. The differences were not statistically significant. MSCs, mesenchymal stem cells.

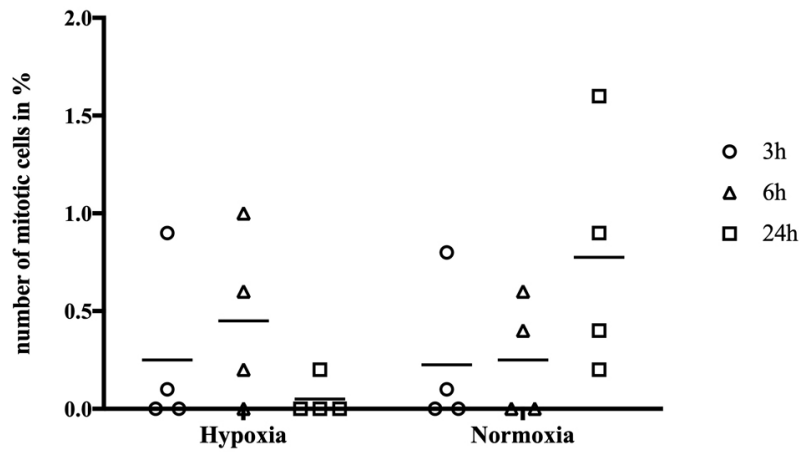

Figure 2. Proportion of mitotic MSCs after incubation under hypoxia and normoxia. The proportion of mitotic MSCs under normoxia and hypoxia ranged from 0.2 to $0.8 \%$. The experiments were independently performed four times, and the lines on the graph show the arithmetic mean. The differences were not statistically significant. MSCs, mesenchymal stem cells.

angiogenesis and chemotaxis (Table I). After MSCs were cultivated under hypoxia, the supernatant showed weak signals for interleukin (IL)-2, $-3,-4,-5,-8$ and -10 , the chemokines monocyte chemoattractant protein-1 (MCP-1), regulated and normal $\mathrm{T}$ cell expressed and secreted and thymus- and activation-regulated chemokine. Meanwhile, there was a strong signal for IL-6. After MSCs were cultivated under normoxia, the supernatant showed a weak signal for MCP-1 and a strong signal for IL-6 (Fig. 5).

Analysis of FaDu cell viability and proliferation. FaDu cells were incubated for 48 and $72 \mathrm{~h}$ in fresh DMEM with supplements (FaDu-fre), normoxic preconditioned MSC supernatant (FaDu-nor) and hypoxic preconditioned MSC supernatant (FaDu-hyp). After $48 \mathrm{~h}$ under hypoxia, the viabilities of the FaDu-fre, FaDu-nor and FaDu-hyp groups were 53.8, 53.3 and $52.7 \%$, respectively. After $48 \mathrm{~h}$ under normoxia, the corresponding viabilities were $70.3,68.0$ and $77.2 \%$, respectively. After $72 \mathrm{~h}$ under hypoxia, the viabilities of the FaDu-fre, FaDu-nor and FaDu-hyp groups were 54.9, 52.8 and 55.0\%, respectively. After $72 \mathrm{~h}$ under normoxia, the corresponding viabilities were $73.6,73.8$ and $67.4 \%$, respectively. These differences were not statistically significant. After $48 \mathrm{~h}$, $\mathrm{P}=0.80$ for different media and $\mathrm{P}=0.004$ for different levels of oxygenation by two-way ANOVA, but the difference for levels 

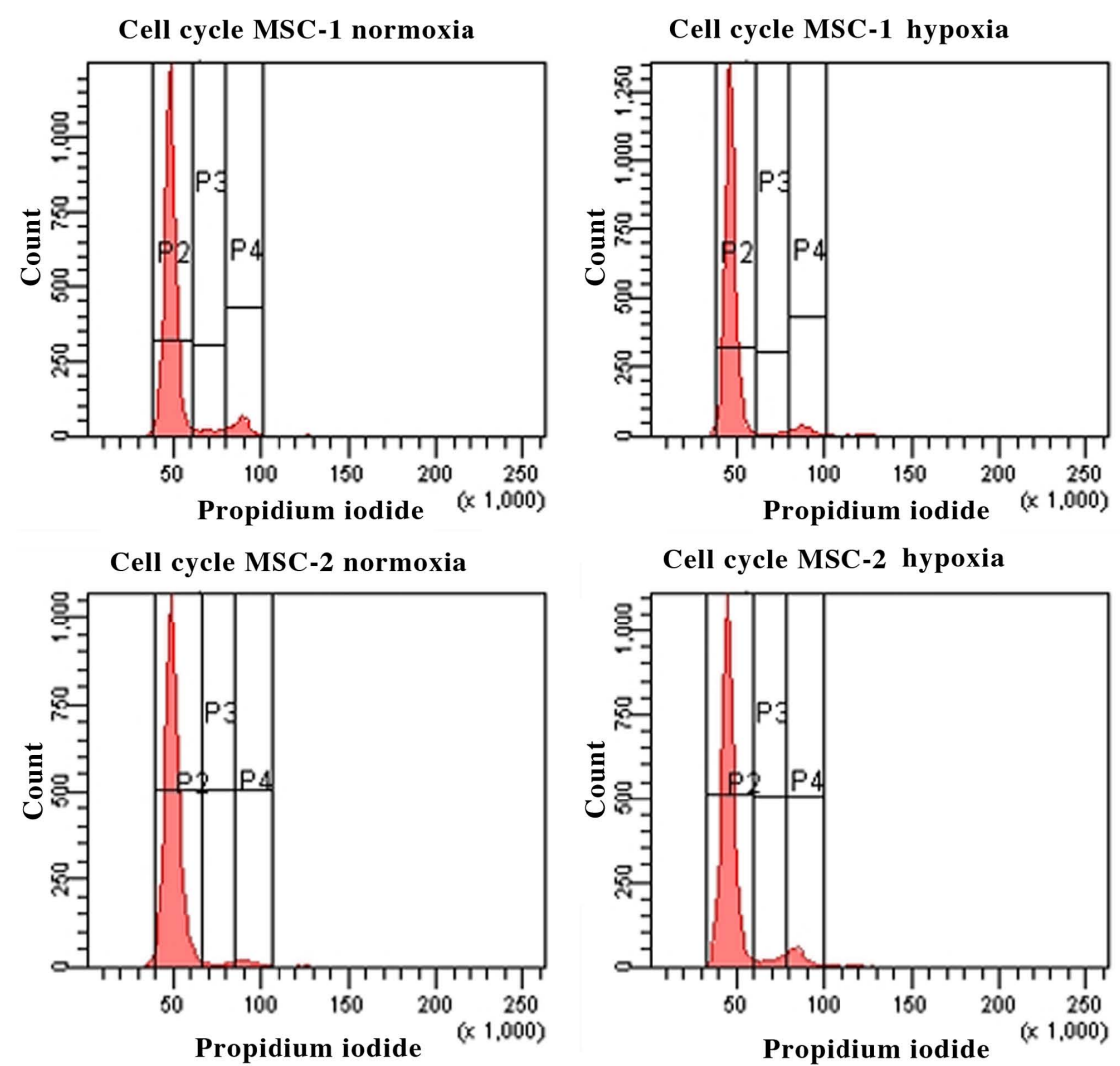

Cell cycle MSC-2 hypoxia

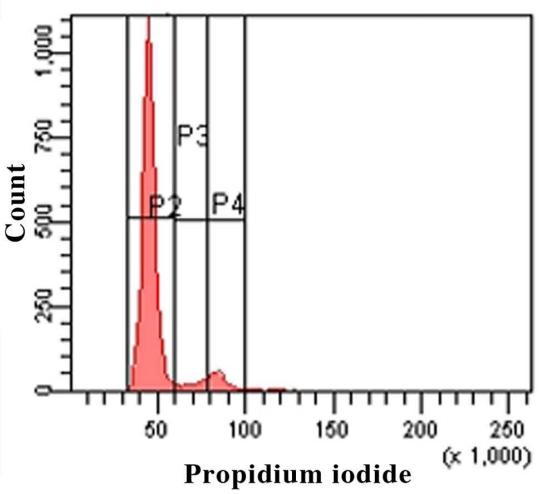

Cell cycle MSC-3 normoxia

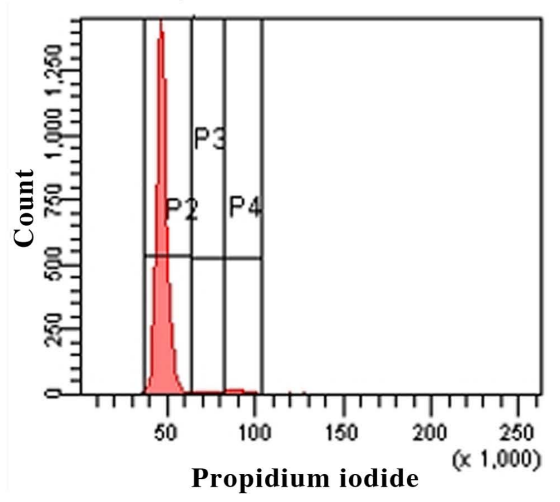

Cell cycle MSC-3 hypoxia
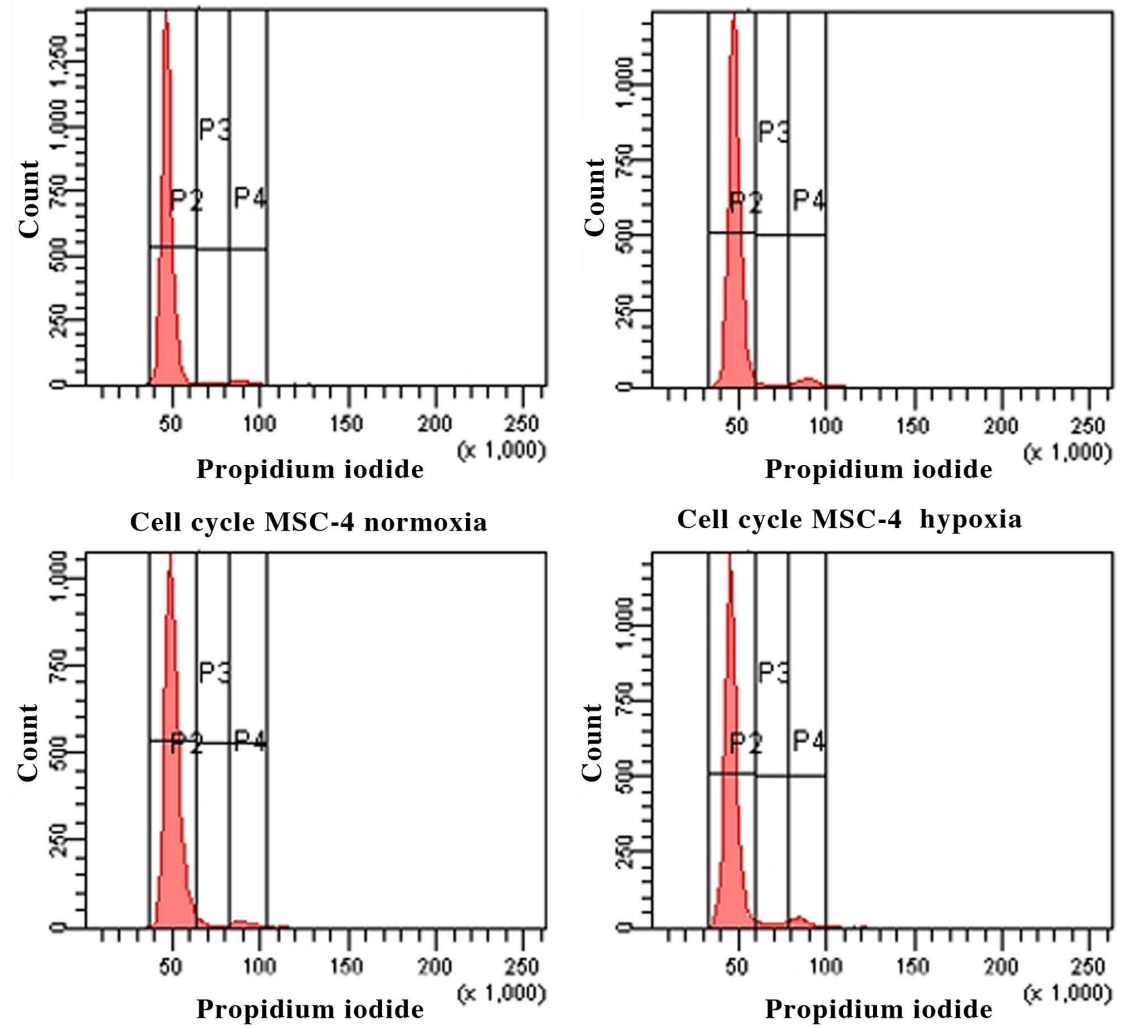

Figure 3. Histograms of the cell cycle analysis for MSCs under hypoxia and normoxia. The histograms on the left side show the cell cycle analysis of MSCs under normoxia for four repetitions (MSC-1-4), the histograms on the right side show the cell cycle analysis of MSCs under $24 \mathrm{~h}$ of hypoxia for four repetitions (MSC-1-4). The x-axis shows the intercalation of the nucleic acid stain propidium iodide which correlates with the DNA content of the cells, and the y-axis shows the cell count. $\mathrm{P} 2, \mathrm{G}_{0} / \mathrm{G}_{1}$ phase; $\mathrm{P} 3, \mathrm{~S}$ phase; $\mathrm{P} 4, \mathrm{G}_{2} / \mathrm{M}$ phase; MSCs, mesenchymal stem cells.

of oxygenation was not significant after correction for multiple testing (data not shown). After $72 \mathrm{~h}, \mathrm{P}=0.85$ for different media and $\mathrm{P}=0.002$ for different levels of oxygenation by two-way ANOVA, but the difference for levels of oxygenation was 


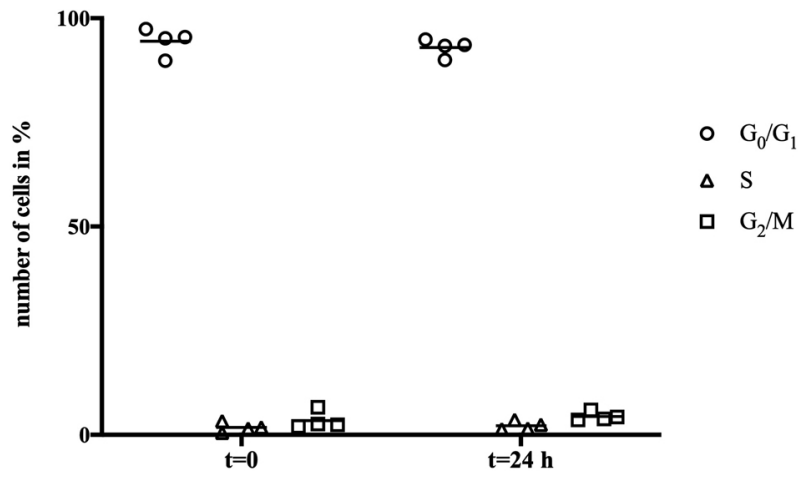

Figure 4. Analysis of the cell cycle in MSCs under hypoxia and normoxia. The proportion of cells in $\mathrm{G}_{0} / \mathrm{G}_{1}, \mathrm{~S}$ and $\mathrm{G}_{2} / \mathrm{M}$ phase was $93-94 \%, 2$ and 3-4\%, respectively. The experiments were independently performed four times, and the lines on the graph show the arithmetic mean. The differences were not statistically significant.

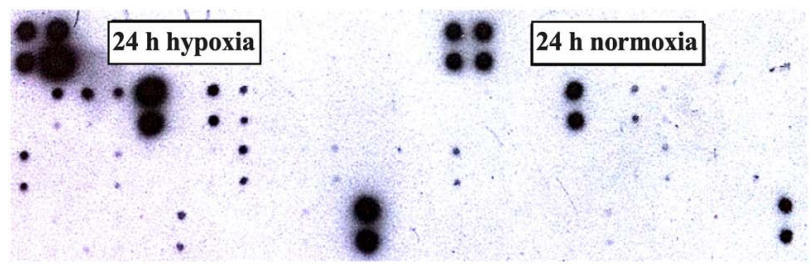

Figure 5. Cytokine assay conducted with the supernatants of MSCs after cultivation under hypoxia and normoxia. The supernatant of MSCs under $24 \mathrm{~h}$ of hypoxia showed a strong signal for IL-6 and weak signals for several other cytokines. The supernatant of MSCs under $24 \mathrm{~h}$ of normoxia showed a weaker IL-6 signal. MSCs, mesenchymal stem cells; IL, interleukin.

not significant after correction for multiple testing (data not shown) (Fig. 6).

After $48 \mathrm{~h}$ under hypoxia, the FaDu cell count was $5.7 \times 10^{5}, 4.2 \times 10^{5}$ and $5.9 \times 10^{5}$ for the FaDu-fre, FaDu-nor and FaDu-hyp groups, respectively. After $48 \mathrm{~h}$ under normoxia, the corresponding cell count was $1.0 \times 10^{6}, 7.1 \times 10^{5}$ and $9.2 \times 10^{5}$, respectively. After $72 \mathrm{~h}$ under hypoxia, the FaDu cell count was $5.4 \times 10^{5}, 5.9 \times 10^{5}$ and $5.5 \times 10^{5}$ for the FaDu-fre, FaDu-nor and FaDu-hyp groups, respectively. After $72 \mathrm{~h}$ under normoxia, the corresponding cell count was $1.9 \times 10^{6}, 1.5 \times 10^{6}$ and $1.2 \times 10^{6}$, respectively. These differences were not statistically significant (after $48 \mathrm{~h}, \mathrm{P}=0.48$ for different media, $\mathrm{P}=0.047$ for different levels of oxygenation by two-way ANOVA, but these differences were not significant after correction for multiple testing; after $72 \mathrm{~h}, \mathrm{P}=0.52$ for different media, $\mathrm{P}=0.001$ for different levels of oxygenation by two-way ANOVA, but these differences were not significant after correction for multiple testing; Fig. 7).

\section{Discussion}

Human MSCs could serve as a drug-delivery system because they can be recruited by injured, inflamed or tumorous tissue (26). Their simple isolation from various tissues, the possibility of their ex vivo expansion, their multipotent differentiation potential and their ability to evade the immune system allows the use of human MSCs in an allogeneic setting, thus in a genetically different individual (26). Thus, MSCs have already been tested as carriers for viral vectors in gene transfer in vitro and in vivo $(27,28)$. However, a hazard of this method is possible integration of the viral genome into the host genome, which can induce insertional mutagenesis and thus oncogene activation $(29,30)$.

The effects of MSCs on tumors are divisive because the cellular interactions are barely understood. On the one hand, MSCs were shown to enhance the metastatic potential of breast cancer cells and migrate into the tumor stroma as tumor-associated fibroblasts, thereby promoting tumor invasion $(31,32)$. On the other hand, MSCs can also have antitumorigenic effects, as they have been shown to inhibit the growth of Kaposi's sarcoma in vivo and liver cancer cell proliferation in vitro $(16,33)$. A possible explanation for these discrepancies could be the non-standard use of MSCs of different origins, and their standardization would be useful for purification and allow improved characterization of MSCs (6). Another reason for these differing results could be the heterogenic characteristics of MSCs. According to Pevsner et al (34), MSCs exhibit variability in their phenotypes, including their proliferative capacity, expression of cell surface markers and ability to secrete cytokines. This heterogenicity could explain discrepancies in the aforementioned results, such as varying concentrations of secreted cytokines in the cytokine assay or in each repetition of the analysis of FaDu cell viability and proliferation at 48 and $72 \mathrm{~h}$.

The interaction of tumor cells and MSCs is largely determined by the tumor microenvironment (35). One key aspect in this regard is tumor hypoxia, which is the reason for the limited success of oncological treatment, as hypoxic intratumoral areas exhibit decreased levels of chemotherapeutic agents and radiation resistance compared with normoxic areas (3). An important hypoxic marker is the transcription factor hypoxia-inducible factor, which stimulates the malignant progression of tumors and is the origin of physiological and pathological adaptations. An example for such adaptions is the neoangiogenesis, which promotes further tumor growth and facilitates the metastatic spread of tumor cells (36). The response of MSCs to hypoxic conditions, however, is controversial, as both damaging and restorative effects have been observed (37). For example, a short-time effect of hypoxia on MSCs is apoptosis (38), while MSCs display enhanced proliferation long-time exposure to hypoxia (39). The interaction of tumor cells and MSCs under hypoxia is rarely examined. Recently, MSCs were shown to promote tumor cell proliferation after conditioning in hypoxic media (40).

The results of the present study demonstrated that MSCs can influence tumor cell proliferation and that oxygenation plays a crucial role in this context. MSCs showed no significant differences in viability after incubation under normoxic and hypoxic conditions. Micronuclei, an indicator for chromosomal damage (41), tended to be more frequent after incubation under normoxia for longer periods, but the number of micronuclei declined under hypoxia. The proportion of cells undergoing mitosis, an indicator of proliferation (42), was lower after $24 \mathrm{~h}$ of hypoxia compared with after $24 \mathrm{~h}$ of normoxia, but the differences were not statistically significant. This result provides initial insight into the limited survival conditions of MSCs under hypoxia. However, cell cycle analysis did not indicate any differences between normoxic and 
Table I. Cytokine assay map.

\begin{tabular}{ccccccccccccc}
\hline & A & B & C & D & E & F & \multicolumn{1}{c}{ G } & H & I & J & K & L \\
\hline 1 & + & + & - & - & ENA-78 & G-CSF & GM-CSF & GRO & GRO- $\alpha$ & I-309 & IL-1 $\alpha$ & IL-1 $\beta$ \\
2 & + & + & - & - & ENA-78 & G-CSF & GM-CSF & GRO & GRO- $\alpha$ & I-309 & IL-1 $\alpha$ & IL-1 $\beta$ \\
3 & IL-2 & IL-3 & IL-4 & IL-5 & IL-6 & IL-7 & IL-8 & IL-10 & IL-12 & IL-13 & IL-15 & IFN- $\gamma$ \\
4 & IL-2 & IL-3 & IL-4 & IL-5 & IL-6 & IL-7 & IL-8 & IL-10 & IL-12 & IL-13 & IL-15 & IFN- $\gamma$ \\
5 & MCP-1 & MCP-2 & MCP-3 & M-CSF & MDC & MIG & MIP-1 & RANTES & SCF & SDF-1 & TARC & TGF- $\beta 1$ \\
6 & MCP-1 & MCP-2 & MCP-3 & M-CSF & MDC & MIG & MIP-1 & RANTES & SCF & SDF-1 & TARC & TGF- $\beta 1$ \\
7 & TNF- $\alpha$ & TNF- $\beta$ & EGF & IGF-1 & ANG & OSM & THPO & VEGF & PDGF & Leptin & - & + \\
8 & TNF- $\alpha$ & TNF- $\beta$ & EGF & IGF-1 & ANG & OSM & THPO & VEGF & PDGF & Leptin & - & + \\
\hline
\end{tabular}

The map shows the cytokines detected in the supernatants of MSCs under hypoxia and normoxia. Each element in the table represents a chemiluminescence signal in Fig. 5. The signal intensity corresponds to the cytokine concentration. MSCs, mesenchymal stem cells; ENA, epithelial-derived neutrophil-activating protein; G-CSF, granulocyte-colony stimulating factor; GM-CSF, granulocyte-macrophage colony-stimulating factor; GRO, growth-regulated oncogene; I-309, inflammatory cytokine 309; IL, interleukin; IFN, interferon; MCP, monocyte chemoattractant protein; M-CSF, macrophage colony-stimulating factor; MDC, macrophage-derived chemokine; MIG, monokine induced by gamma interferon; MIP, macrophage inflammatory protein; RANTES, regulated and normal T cell expressed and secreted; SCF, stem cell factor; SDF, stromal cell-derived factor; TARC, thymus and activation regulated chemokine; TGF, tumor growth factor; TNF, tumor necrosis factor; EGF, epidermal growth factor; IGF, insulin-like growth factor; ANG, angiogenin; OSM, oncostatin M; THPO, thrombopoietin; VEGF, vascular endothelial growth factor; PDGF, platelet-derived growth factor.

A

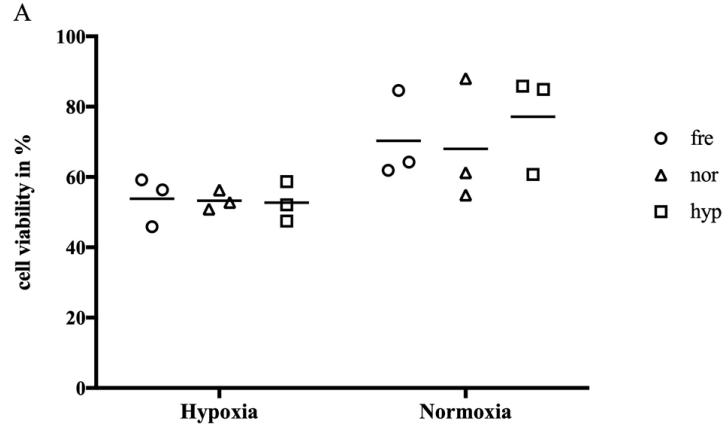

B

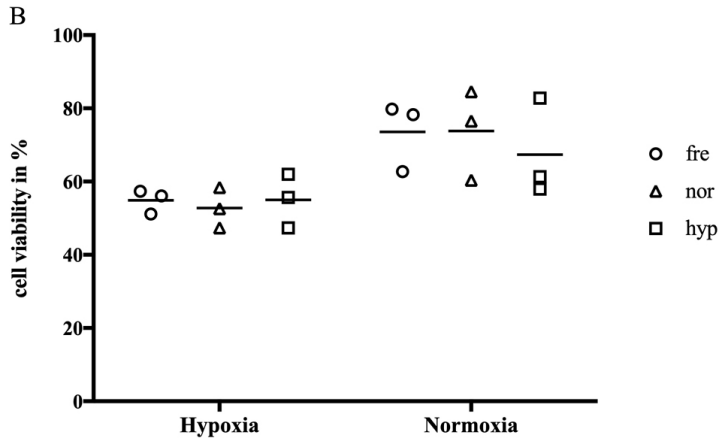

Figure 6. Viability of FaDu cells in preconditioned medium at different time points. (A) After $48 \mathrm{~h}$, the viability of FaDu cells in preconditioned medium ranged from 52.7 to $53.8 \%$ under hypoxia and from 68.0 to $77.2 \%$ under normoxia. The differences were not statistically significant. (B) After $72 \mathrm{~h}$, the viability of FaDu cells in the preconditioned media ranged from 52.8 to $55.0 \%$ under hypoxia and from 67.4 to $73.8 \%$ under normoxia. The differences were not statistically significant. All experiments were independently performed four times, and the lines on the graph show the arithmetic mean. Fre, fresh Dulbecco's Modified Eagle's Medium with supplements; Hyp, hypoxic preconditioned MSC supernatant; Nor, normoxic preconditioned MSC supernatant; MSCs, mesenchymal stem cells.

hypoxic MSCs. The use of preconditioned MSC supernatants had an impact on the viability and proliferation of FaDu cells.

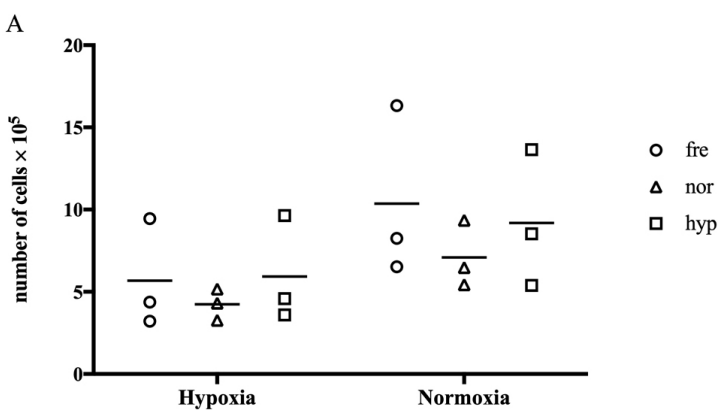

B

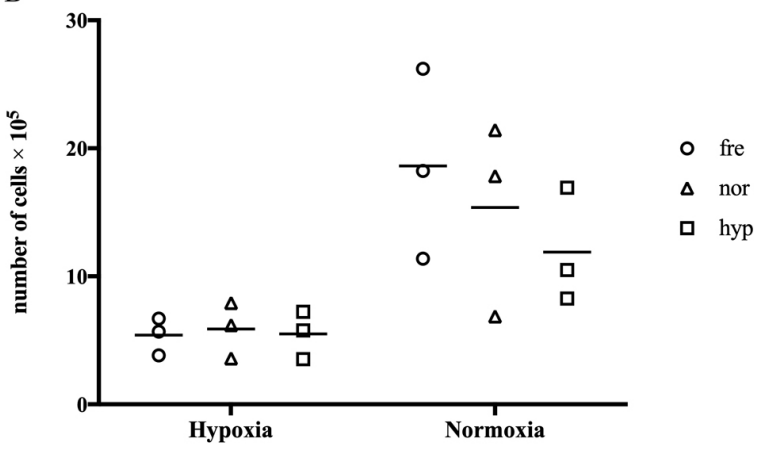

Figure 7. Proliferation of FaDu cells in preconditioned medium after (A) $48 \mathrm{~h}$ and (B) $72 \mathrm{~h}$. (A) After $48 \mathrm{~h}$, the FaDu cell count was between $4.2 \times 10^{5}$ and $5.9 \times 10^{5}$ under hypoxia and between $7.1 \times 10^{5}$ and $1.0 \times 10^{6}$ under normoxia. The differences were not statistically significant. (B) After $72 \mathrm{~h}$, the FaDu cell count was between $5.4 \times 10^{5}$ and $5.9 \times 10^{5}$ under hypoxia and between $1.2 \times 10^{6}$ and $1.9 \times 10^{6}$ under normoxia. The differences were not statistically significant. All the experiments were independently performed four times, and the lines on the graph show the arithmetic mean. Fre, fresh Dulbecco's Modified Eagle's Medium with supplements; Hyp, hypoxic preconditioned MSC supernatant; Nor, normoxic preconditioned MSC supernatant.

Such effects were not detected in tumor cells incubated under hypoxia, as their survival was limited, and the cells under 
all three conditions reached the same level of proliferation. Under normoxia, however, the FaDu cell viability and cell count were increased in hypoxic preconditioned medium. This implied that beneficial factors like cytokines were secreted by MSCs incubated under hypoxia. After $24 \mathrm{~h}$, more cells in the FaDu-hyp group lost this survival benefit, and those in the FaDu-nor group exhibited increased proliferation. This could indicate that the benefits of the cytokines are short-lived. A limitation of these results is the relatively small sample size, which is why it would be useful to validate these analyses with a larger sample size. An additional limitation is that the temporal aspect was not examined for an incubation of the MSCs for $>24 \mathrm{~h}$, and for FaDu cells for $>72 \mathrm{~h}$. These aspects would be interesting to investigate in further studies.

The cytokine assay identified high levels of IL-6 in the preconditioned MSC media. IL- 6 was increased in patients with head and neck carcinomas compared to individuals in the control group (43). IL-6 is a multifunctional regulator of the immune response and hematopoiesis that can directly influence the proliferation and invasion potential of head and neck cancer cells (44). One study detected platinum resistance mediated by IL- 6 in ovarian cancer cells (45). A conceivable mechanism for this resistance is the paracrine influence of tumor cells by their secretion of this cytokine, as proposed by Scherzad et al (46) in their work on the paclitaxel resistance of HLaC78 tumor cells (47). Additionally, other ILs and cytokines secreted by MSCs promote tumor growth in different solid tumors and hematological malignancies $(17,48)$. For example, in the conditioned medium of MSCs, periostin was found to promote the proliferation of head and neck cancer cells (49). On the other hand, IL-1 $\beta$ from the conditioned medium of $\mathrm{FaDu}$ cells mediates a proinflammatory and possibly protumorigenic response in MSCs (50).

Another clinically relevant effect of MSCs on tumor cells is their interaction with the immune system. As a result of interplay between different molecular mechanisms, such as the expression of surface antigens like Programmed cell death 1 ligand 1, or the secretion of cytokines, MSCs can disturb the proper interaction of lymphocytes with tumor cells and facilitate immune escape, that is the avoidance of recognition and attack by the immune system (51). The cytokine transforming growth factor $\beta$, for instance, plays a crucial role in tumor progression by exerting immunosuppressive effects in the tumor microenvironment (52). However, these immunosuppressive mechanisms could be reversed in vitro by activating lymphocytes with aminobisphosphonates (53). Preoperative administration of IL-12 led to the intratumoral accumulation of natural killer cells in patients with HNSCC, suggesting stimulation of the immune response against the tumor. Patients, irrespectively of IL-12 treatment, with a high number of natural killer cells in the primary tumor had a better overall survival than those with a low number (54). Likewise, targeted elimination of MSCs could provide a tool to eliminate their protumorigenic effects (48), for example genetic modification of MSCs which produce retroviral vectors could serve as an approach to disrupt tumor growth by inducing apoptosis (55).

These and further promising results focus on MSCs as candidates for targeted tumor therapy. The results of this work provide further evidence of the role of MSCs in influencing the proliferation of tumor cells under hypoxia and normoxia.

\section{Acknowledgements}

Not applicable.

\section{Funding}

No funding was received.

\section{Availability of data and materials}

All data generated or analyzed during this study are included in this published article.

\section{Authors' contributions}

CW performed all experiments, analyzed the results and was the primary author of the manuscript. MB, TM and TG contributed to the design of the experiments and the interpretation of the results. AS and SH conceived the study, analyzed the results and were major contributors to the manuscript. NK and RH analyzed the data and were major contributors to the manuscript. All authors read and approved the final manuscript.

\section{Ethics approval and consent to participate}

The Ethics Committee of the Medical Faculty, University of Wuerzburg approved the present study (Wuerzburg, Germany; approval no. 72/06). All patients provided written informed consent.

\section{Patient consent for publication}

Not applicable.

\section{Competing interests}

The authors declare that they have no competing interests.

\section{References}

1. Vaupel P, Mayer A and Höckel M: Tumor hypoxia and malignant progression. Methods Enzymol 31: 335-354, 2004.

2. Becker A, Hänsgen $G$, Bloching $M$, Weigel $C$, Lautenschläger $C$ and Dunst $\mathrm{J}$ : Oxygenation of squamous cell carcinoma of the head and neck: Comparison of primary tumors, neck node metastases, and normal tissue. Int J Radiat Oncol Biol Phys 42: 35-41, 1998.

3. Horsman MR, Mortensen LS, Petersen JB, Busk M and Overgaard J: Imaging hypoxia to improve radiotherapy outcome. Nat Rev Clin Oncol 9: 674-687, 2012.

4. Moritake S, Taira S, Ichiyanagi Y, Morone N, Song SY, Hatanaka T, Yuasa S and Setou M: Functionalized nano-magnetic particles for an in vivo delivery system. J Nanosci Nanotechnol 7: 937-944, 2007.

5. Hu YL, Huang B, Zhang TY, Miao PH, Tang GP Tabata Y and Gao JQ: Mesenchymal stem cells as a novel carrier for targeted delivery of gene in cancer therapy based on nonviral transfection. Mol Pharm 9: 2698-2709, 2012.

6. Scherzed A, Hackenberg S, Radeloff A, Froelich K, Rak K, Hagen R and Kleinsasser N: Human mesenchymal stem cells promote cancer motility and cytokine secretion in vitro. Cells Tissues Organs 198: 327-337, 2013.

7. Wei X, Yang X, Han ZP, Qu FF, Shao L and Shi YF: Mesenchymal stem cells: A new trend for cell therapy. Acta Pharmacol Sin 34: 747-754, 2013. 
8. Dominici M, Le Blanc K, Mueller I, Slaper-Cortenbach I, Marini F, Krause D, Deans R, Keating A, Prockop D and Horwitz E: Minimal criteria for defining multipotent mesenchymal stromal cells. The international society for cellular therapy position statement. Cytotherapy 8: 315-317, 2006.

9. Mohammadian M, Shamsasenjan K, Nezhad PL, Talebi M, Jahedi M, Nickkhah H, Minayi N and Pour AM: Mesenchymal stem cells: New aspect in cell-based regenerative therapy. Adv Pharm Bull 3: 433-437, 2013.

10. Malek S, Kaplan E, Wang JF, Ke Q, Rana JS, Chen Y, Rahim BG Li M, Huang Q, Xiao YF, et al: Successful implantation of intravenously administered stem cells correlates with severity of inflammation in murine myocarditis. Pflugers Arch 452: 268-275, 2006

11. Asahara T, Masuda H, Takahashi T, Kalka C, Pastore C, Silver M, Kearne M, Magner M and Isner JM: Bone marrow origin of endothelial progenitor cells responsible for postnatal vasculogenesis in physiological and pathological neovascularization. Circ Res 85: 221-228, 1999.

12. Crisan M, Yap S, Casteilla L, Chen CW, Corselli M, Park TS, Andriolo G, Sun B, Zheng B, Zhang L, et al: A perivascular origin for mesenchymal stem cells in multiple human organs. Cell Stem Cell 3: 301-313, 2008.

13. Spaeth EL, Kidd S and Marini FC: Tracking inflammation-induced mobilization of mesenchymal stem cells. Methods Mol Biol 904: 173-190, 2012

14. Kidd S, Caldwell L, Dietrich M, Samudio I, Spaeth EL, Watson K, Shi Y, Abbruzzese J, Konopleva M, Andreeff M and Marini FC: Mesenchymal stromal cells alone or expressing interferon-beta suppress pancreatic tumors in vivo, an effect countered by anti-inflammatory treatment. Cytotherapy 12: 615-625, 2010

15. Rhodes LV, Muir SE, Elliott S, Guillot LM, Antoon JW Penfornis P, Tilghman SL, Salvo VA, Fonseca JP, Lacey MR, et al: Adult human mesenchymal stem cells enhance breast tumorigenesis and promote hormone independence. Breast Cancer Res Treat 121: 293-300, 2010

16. Khakoo AY, Pati S, Anderson SA, Reid W, Elshal MF, Rovira II, Nguyen AT, Malide D, Combs CA, Hall G, et al: Human mesenchymal stem cells exert potent antitumorigenic effects in a model of kaposi's sarcoma. J Exp Med 203: 1235-1247, 2006.

17. Triaca V, Carito V, Fico E, Rosso P, Fiore M, Ralli M, Lambiase A Greco A and Tirassa P: Cancer stem cells-driven tumor growth and immune escape: The janus face of neurotrophins. Aging (Albany NY) 11: 11770-11792, 2019.

18. Madrigal M, Rao KS and Riordan NH: A review of therapeutic effects of mesenchymal stem cell secretions and induction of secretory modification by different culture methods. J Transl Med 12: 260, 2014

19. Ahluwalia A and Tarnawski AS: Critical role of hypoxia sensor-HIF-1 $\alpha$ in VEGF gene activation. Implications for angiogenesis and tissue injury healing. Curr Med Chem 19: 90-97, 2012

20. Chang CP, Chio CC, Cheong CU, Chao CM, Cheng BC and Lin MT: Hypoxic preconditioning enhances the therapeutic potential of the secretome from cultured human mesenchymal stem cells in experimental traumatic brain injury. Clin Sci (Lond) 124: 165-176, 2013.

21. Li S, Zhang Y, Shao G, Yang M, Niu J, Lv G and Ji X: Hypoxic preconditioning stimulates angiogenesis in ischemic penumbra after acute cerebral infarction. Neural Regen Res 8: 2895-2903, 2013.

22. Yu J, Yin S, Zhang W, Gao F, Liu Y, Chen Z, Zhang M, He J and Zheng S: Hypoxia preconditioned bone marrow mesenchymal stem cells promote liver regeneration in a rat massive hepatectomy model. Stem Cell Res Ther 4: 83, 2013.

23. Lavrentieva A, Majore I, Kasper C and Hass R: Effects of hypoxic culture conditions on umbilical cord-derived human mesenchymal stem cells. Cell Commun Signal 8: 18, 2010.

24. Lee RH, Kim B, Choi I, Kim H, Choi HS, Suh K, Bae YC and Jung JS: Characterization and expression analysis of mesenchymal stem cells from human bone marrow and adipose tissue. Cell Physiol Biochem 14: 311-324, 2004.

25. Rangan SR: A new human cell line $(\mathrm{FaDu})$ from a hypopharyngeal carcinoma. Cancer 29: 117-121, 1972.

26. Krueger TE, Thorek DL, Denmeade SR, Isaacs JT and Brennen WN: Concise review: Mesenchymal stem cell-based drug delivery: The good, the bad, the ugly, and the promise. Stem Cells Transl Med 7: 651-663, 2018.

27. Kucerova L, Altanerova V, Matuskova M, Tyciakova $S$ and Altaner C: Adipose tissue-derived human mesenchymal stem cells mediated prodrug cancer gene therapy. Cancer Res 67: 6304-6313, 2007.
28. Cavarretta IT, Altanerova V, Matuskova M, Kucerova L, Culig Z and Altaner C: Adipose tissue-derived mesenchymal stem cells expressing prodrug-converting enzyme inhibit human prostate tumor growth. Mol Ther 18: 223-231, 2010

29. Anson DS: The use of retroviral vectors for gene therapy-what are the risks? A review of retroviral pathogenesis and its relevance to retroviral vector-mediated gene delivery. Genet Vaccines Ther 13: 9, 2004

30. Fan $\mathrm{H}$ and Johnson C: Insertional oncogenesis by non-acute retroviruses: Implications for gene therapy. Viruses 3: 398-422, 2011.

31. Karnoub AE, Dash AB, Vo AP, Sullivan A, Brooks MW, Bell GW, Richardson AL, Polyak K, Tubo R and Weinberg RA: Mesenchymal stem cells within tumour stroma promote breast cancer metastasis. Nature 449: 557-563, 2007.

32. De Wever O and Mareel M: Role of tissue stroma in cancer cell invasion. J Pathol 200: 429-447, 2003.

33. Hou L, Wang X, Zhou Y, Ma H, Wang Z, He J, Hu H, Guan W and Ma Y: Inhibitory effect and mechanism of mesenchymal stem cells on liver cancer cells. Tumor Biol 35: 1239-1250, 2014

34. Pevsner-Fischer M, Levin S and Zipori D: The origins of mesenchymal stromal cell heterogeneity. Stem Cell Rev Rep 7: 560-568, 2011.

35. Melzer C, Yang Y and Hass R: Interaction of MSC with tumor cells. Cell Commun Signal 14: 20, 2016.

36. Dachs GU and Tozer GM: Hypoxia modulated gene expression: Angiogenesis, metastasis and therapeutic exploitation. Eur J Cancer 36: 1649-1660, 2000.

37. Buravkova LB, Andreeva ER, Gogvadze V and Zhivotovsky B: Mesenchymal stem cells and hypoxia: Where are we? Mitochondrion 19: 105-112, 2014.

38. Chang W, Song BW, Lim S, Song H, Shim CY, Cha MJ, Ahn DH, Jung YG, Lee DH, Chung JH, et al: Mesenchymal stem cells pretreated with delivered hph-1-hsp70 protein are protected from hypoxia-mediated cell death and rescue heart functions from myocardial injury. Stem Cells 27: 2283-2292, 2009.

39. Basciano L, Nemos C, Foliguet B, de Isla N, de Carvalho M, Tran N and Dalloul A: Long term culture of mesenchymal stem cells in hypoxia promotes a genetic program maintaining their undifferentiated and multipotent status. BMC Cell Biol 30: 12, 2011.

40. Liu Y, Ren H, Zhou Y, Shang L, Zhang Y, Yang F and Shi X: The hypoxia conditioned mesenchymal stem cells promote hepatocellular carcinoma progression through YAP mediated lipogenesis reprogramming. J Exp Clin Cancer Res 38: 228, 2019.

41. Evans HJ, Neary GJ and Williamson FS: The relative biological efficiency of single doses of fast neutrons and gamma-rays on vicia faba roots and the effect of oxygen. Part II. Chromosone damage: The production of micronuclei. Int J Radiat Biol Relat Stud Phys Chem Med 1: 216-229, 1959.

42. Haapasalo H, Pesonen E and Collan Y: Volume corrected mitotic index (M/V-INDEX): The standard of mitotic activity in neoplasms. Pathol Res Pract 185: 551-554, 1989.

43. Chen Z, Malhotra PS, Thomas GR, Ondrey FG, Duffey DC, Smith CW, Enamorado I, Yeh NT, Kroog GS, Rudy S, et al: Expression of proinflammatory and proangiogenic cytokines in patients with head and neck cancer. Clin Cancer Res 5: $1369-1379,1999$

44. Kanazawa T, Nishino H, Hasegawa M, Ohta Y, Iino Y, Ichimura K and Noda Y: Interleukin-6 directly influences proliferation and invasion potential of head and neck cancer cells. Eur Arch Otorhinolaryngol 264: 815-821, 2007.

45. Cohen S, Bruchim I, Graiver D, Evron Z, Oron-Karni V, Pasmanik-Chor M, Eitan R, Bernheim J, Levavi H, Fishman A and Flescher E: Platinum-Resistance in ovarian cancer cells is mediated by IL-6 secretion via the increased expression of its target cIAP-2. J Mol Med 91: 357-368, 2013.

46. Scherzad A, Steber M, Gehrke T, Rak K, Froelich K, Schendzielorz P, Hagen R, Kleinsasser N and Hackenberg S: Human mesenchymal stem cells enhance cancer cell proliferation via IL- 6 secretion and activation of ERK1/2. Int J Oncol 47: 391-397, 2015.

47. Scherzed A, Hackenberg S, Froelich K, Kessler M, Koehler C, Hagen R, Radeloff A, Friehs G and Kleinsasser N: BMSC enhance the survival of paclitaxel treated squamous cell carcinoma cells in vitro. Cancer Biol Ther 11: 349-357, 2011.

48. Poggi A and Giuliani M: Mesenchymal stromal cells can regulate the immune response in the tumor microenvironment. Vaccines 4: 41, 2016 
49. Liu C, Feng X, Wang B, Wang X, Wang C, Yu M, Cao G and Wang $\mathrm{H}$ : Bone marrow mesenchymal stem cells promote head and neck cancer progression through periostin-mediated phosphoinositide 3-kinase/akt/mammalian target of rapamycin. Cancer Sci 109: 688-698, 2018.

50. Al-toub M, Almusa A, Almajed M, Al-Nbaheen M, Kassem M, Aldahmash A and Alajez NM: Pleiotropic effects of cancer cells'secreted factors on human stromal (mesenchymal). Stem Cells Res Ther 17: 114, 2013.

51. Poggi A, Musso A, Dapino I and Zocchi MR: Mechanisms of tumor escape from immune system: Role of mesenchymal stromal cells. Immunol Lett 159: 55-72, 2014.

52. Siegel PM and Massagué J: Cytostatic and apoptotic actions of TGF- $\beta$ in homeostasis and cancer. Nat Rev Cancer 3: 807-820, 2003.
53. Musso $A$, Catellani $S$, Canevali $P$, Tavella $S$, Venè $R$ Boero S, Pierri I, Gobbi M, Kunkl A, Ravetti JL, et al: Aminobisphosphonates prevent the inhibitory effects exerted by lymph node stromal cells on anti-tumor Vd $2 \mathrm{~T}$ lymphocytes in non-hodgkin lymphomas. Haematologica 99: 131-139, 2014.

54. Van Herpen CM, Van Der Laak JA, De Vries IJ, van Krieken JH, de Wilde PC, Balvers MG, Adema GJ and De Mulder PH: Intratumoral recombinant human interleukin-12 administration in head and neck squamous cell carcinoma patients modifies locoregional lymph node architecture and induces natural killer cell infiltration in the primary tumor. Clin Cancer Res 11: 1899-1909, 2005

55. Uchibori R, Tsukahara T, Ohmine $\mathrm{K}$ and Ozawa K: Cancer gene therapy using mesenchymal stem cells. Int J Hematol 99: $377-382,2014$. 